\title{
The Role of Self-assessment Guide on Improving Iranian EFL Learners' Writing: The Portfolio Approach
}

Farnaz Sahebkheir*

Department of English Language Teaching, Tabriz Branch, Islamic Azad University, Tabriz, Iran

Corresponding Author: Farnaz Sahebkheir, E-mail: farnaz.sahebkheir@yahoo.com

\section{ARTICLE INFO}

Article history

Received: June 5, 2018

Accepted: August 16, 2018

Published: November 01, 2018

Volume: 7 Issue: 6

Advance access: September 2018

Conflicts of interest: None

Funding: None

\begin{abstract}
Writing skill is one of the most difficult skills to be taught. Teachers try to find new ways to teach it especially via student-centered approaches. Self-assessment portfolio can be one of these learner-centered methods for improving learners writing skill. This study aims to investigate the effect of self-assessment portfolio on Iranian EFL students' writing production. Two groups were selected through a KET test and they were randomly assigned as a control and an experimental group. The experimental group had to use a self-assessment guide and completed their writing tasks. They reflected and critically analyzed their own writing using the Self-assessment Guide. While the control group did not receive the self-assessment guide and they just received teacher written error correction for their writing tasks. They either did not analyze their written product critically. The experimental group outperformed the control group and the differences were statistically significant. Students in the experimental group engaged in constant critical thinking and developed a strong sense of responsibility for their learning. It can be concluded that teachers should engage their students in self-assessment portfolio to encourage more critical thinking and self-regulation.
\end{abstract}

Key words: EFL, Critical Thinking, Portfolio, Self-assessment, Writing

\section{REVIEW OF LITERATURE}

There are different approaches towards teaching writing. Focusing on new approaches like student-centeredness can be useful. Teachers should emphasize on more learner centered methods, e.g. Self- assessment Portfolio. In a student centered setting, students are responsible for what and how they want to learn. The learning of a language in a humanistic approach requires that students be a part of the learning cycle, including assessment of language competency. Brindley (2003) states that assessment "should be done with learners, not to them" (p. 316). Self-assessment and peer-assessment have been some of the ways to involve students in the learning cycles. These approaches help students to create an answer that shows what they can do. Brown \& Glasner (1999) believes that these forms of assessment are in contrast to traditional types of assessments that focus mainly on the correct response.

\section{Portfolio Assessment}

Hamp-Lyons and Condon(2000)states, a portfolio is "a collection of texts the writer has produced over a defined period of time to the specifications of a particular context" (p. 261). Paulson, and Meyer (1991, p: 60) claims that:

Portfolio is 'A purposeful collection of a student's work that exhibits his/her efforts, progress, and achievements in one or more areas. The collection must include student participation in selecting contents, the criteria for selection, the criteria for judging merit, and evidence of student self-reflection. They also state that "A portfolio provides a complex and comprehensive view of student performance in context.'

Portfolios show how much students' writing has progressed from the beginning of the term. Therefore, Portfolio assessment has the potential to create positive wash back on students' writing (Hughes, 2003). Arndt(1993) stated that Traditionally, students had to write in a "one-draft, one-reader" context. They received a grade and minimal feedback from the teacher, students may make corrections on their drafts. After that, the learning process is supposedly finished and students are asked to write on another topic. The product approach towards writing focuses on teachers summative judgments rather than helping students to self-assess their own drafts before submitting. Weigle (2007) and Sajedi (2014) believe that the adoption of a portfolio approach in EFL writing classrooms may empower students' active participation in self-evaluating their own work within the writing process. Mousavi(1999, p.275) mentions that teachers respond to the materials not to provide an evaluation with a grade or score but to provide suggestions for revision as well as some general commentary about the individual's development as a writer. At the end of the course, teachers may 
also want to grade the portfolios which represent the results of what the students have learnt and the best work they have produced in the class.

According to Khoosf and Khosravani(2014), the goal of portfolios is to enable the student to show to others their learning and progress. The greatest value of portfolios is that students can become active participants in the learning process and its assessment. Portfolios are collections of students' work selected by the students (with the teacher's guidance) to represent their learning experiences. They usually involve students selecting and gathering samples of their language use into a folder to show to their peers, parents, and others. Furthermore, they claim that portfolios are not just a collection of materials stuffed into a folder. Each piece of the portfolio must be created, collected, and organized in such a way as to demonstrate certain competencies. A portfolio should include information about the activities that produced the portfolio, the process of development (possibly including drafts and revisions), and a narrative in which the student reflectively describes the learning that takes place.

Chabeli(2002) declares the differences between traditional and Portfolio methods of assessment

1. Traditional Evaluation

a. testing knowledge acquired outside the context

b. Limited to pen and paper

c. Traditional tests require the learner to select the correct answers, for whatever reason.

d. Traditional assessment tests are designed to suggest one correct answer for each item.

e. Involves simple elements of activities under evaluation.

2. Portfolio Evaluation

a. Highlights effectively the capacities and competences acquired

b. It involves students in complex activities that reflect very well the priorities and challenges based on discussions, analyzes, engaging in discussion of events, collaboration with colleagues, etc.

c. It requests more elaborate answers, comprehensive, evidence-based.

d. Scoring criteria established in collaboration must take into account the diversity of manifestation and materialization of learning outcomes.

e. Involves simple elements of activities under evaluation. It favors placing the learner in situations similar to real situation and preparing them for social and professional life.

f. It promotes critical thinking and problem solving, creates the potential for gaining autonomy of the learner.

This study aims at investigating the effect of self-assessment portfolio on Iranian EFL students' writing production. This may be investigated via the following research question:

1. Do self-assessed portfolios have any effect on the writing skill of Iranian EFL learners?

\section{METHODOLOGY}

\section{Participants}

The study was conducted with 40 students taking Writing course at Rooze-No English Institute in Tabriz -Iran. They were selected through a KET test to have homogenized groups. They were randomly chosen as the control and experimental groups.

\section{Procedure}

After dividing the participants into a control group and an experimental group based on their language proficiency scores, during a four session discussion basic elements of a good writing were introduced to both control and experimental groups. The aim was generating discussion and getting feedback from both groups to be sure of their awareness of the basic requirements of a good writing. The experimental group was given the Introduction to Self-assessment which included a Self-assessment Guide used by Sajedi (2014). Participants in Control group didn't have access to this Self-assessment Guide. During eight weeks of treatment, the participants wrote eight compositions. The first and the last ones were scored as pre- and post-test. Their writings were rated by two raters to be sure of their inter-rater reliability. The mean of these two raters' scores was used as the final score of every participant's score. Students in the experimental group reflected and critically analyzed their own writing using the Self-assessment Guide. However, after completing their writing, students in the control group just received the score from their teachers. It has to be mentioned that the raters also used the same Self-assessment Guide for evaluating the students' compositions in both groups.

\section{Materials}

Participants in the experimental group rated their own writing according to the given guide.

The guide uses a 4-point Likert scale used as strongly disagree, disagree, agree, and strongly agree. They were scored as 1-4. The sum of ratings for every item was used as the final score of the participants. Maximum score that a respondent can get is out of 64 .

\section{RESULTS}

According to the results, there isn't any significant difference between two groups rating scores in the pre-test. However, there is a significant difference between two groups rating scores in the post-test. This difference is in favor of experimental group. It seems that those students who rated their own writing according to the given self-assessment guide can improve their writing better than control group (Table 1).

\section{DISCUSSION AND CONCLUSION}

Portfolio assessment is an approach to the assessment of students' writing that uses portfolio approach; a portfolio is 
Table 1. Descriptive statistics and independent sample T-test of the scores of the experimental and control groups' writing performance in the pre-test and post-test

\begin{tabular}{llccccccc}
\hline Group & N & Mean & Standard deviation & Sig.(2-tailed) & df & Sig & t & F \\
\hline Control-pre & 20 & 48.43 & 2.25 & 0.89 & 38 & 0.71 & 2.154 & 1.65 \\
Experimental & 20 & 51.21 & 2.87 & 0.87 & 37.12 & & \\
Control-post & 20 & 53.56 & 2.76 & 0.05 & 37 & 0.005 & -2.43 \\
Experimental & 20 & 59.71 & 2.31 & 0.04 & 36.76 & & \\
\hline
\end{tabular}

"a collection of texts the writer has produced over a defined period of time to the specifications of a particular context" (Hirvela \& Sweetland, 2005, p.193). Portfolios show how much students' writing has improved from the beginning of the treatment. As a result, Portfolio assessment has the ability to create positive wash back on students' writing (Hughes, 2003). Traditionally, students have been asked to write in a "one-draft, one-reader" context (Arndt, 1993). Having received a grade and minimal feedback from the teacher, students may make corrections on their drafts. After that, the learning process is supposedly finished and students are asked to write on another topic. The product approach to writing increases students' dependence on a teacher's summative judgments rather than helping students to self-assess their own drafts before submission. The adoption of a portfolio approach in EFL writing classrooms may empower students' active participation in self-evaluating their own work within the writing process (Weigle, 2007). This study has demonstrated how students, teachers, and researchers may benefit from self-assessment. Self-assessment portfolio help students to achieve a clear understanding of the expected learning outcomes, identify their strengths and weaknesses, and set goals for future improvement. By analyzing their own learning, students engage in critical thinking and develop a strong sense of responsibility towards learning. Learners are no longer passively receiving instructions from teachers but actively participate in learning and their own assessment and seeking ways to make further improvement for their production. It can be helpful for teachers to introduce self-assessment as a formal practice to encourage students' involvement and lead to a learner-centered classroom. Self-assessment under teachers' guidance and peers feedback will make teaching and learning integrated. There should be more studies on different genders, language proficiency and different language backgrounds. Furthermore, different language skills like speaking can be studied through portfolio assessment.

\section{REFERENCES}

Arndt, V. (1993). Response to writing: Using feedback to inform the writing process. In M. Brock \& L. Walters (Eds.), Writing around the Pacific Rim(pp.90-114). Clevedon, UK: Multilingual Matters.

Brindley, G. (2003). Classroom-based assessment. In D. Nunan (Eds.), Practical English Language Teaching(pp.309-328). New York: McGraw-Hill.

Brown, S. \& Glasner, A. (1999). Assessment Matters in Higher Education. Buckingham: Open University Press.

Chabeli, M.M. (2002). Portfolio assessment and evaluation: Implications and guidelines for clinical nursing education. Curationis, 25 (3), 4-9.

Hamp-Lyons, L. \& Condon, W. (2000). Assessing the portfolio: Principles for practice, theory and research. Cresskill, NJ: Hampton Press.

Hirvela, A. \& Sweetland, Y. L. (2005). Two case studies of L2 writers' experiences a cross learning-directed portfolio contexts. Assessing Writing, 10,192-213.

Hughes, A. (2003). Testing for language teachers. (2nded.). Cambridge: Cambridge University Press.

Khoosf, S. G., \& Khosravani, M. (2014). Introducing Email Portfolio as a Means of Developing EFL Learner's Autonomy. Procedia - Social and Behavioral Sciences, 98, $504-512$

Mousavi, S. A. (1999). A Dictionary of Language Testing. 2nded. Tehran: Rahnama.

Sajedi, R. (2014). Self- assessment and Portfolio Production of Iranian EFL Learners. Procedia - Social and Behavioral Sciences, 98, 1641 - 1649.

Weigle, S. C. (2007). Teaching writing teachers about assessment. Journal of Second Language Writing, 16(3), 194-209. 